\title{
Study on the Laboratory Construction Innovation of Application-oriented Colleges in Transformation Period
}

\author{
Baichun Miao \\ School of Applied Technology Dalian Ocean University Dalian, Liaoning, 116300 \\ 48278216@qq.com
}

Keywords: Application-oriented college; Transformation; Laboratory construction; Innovation

\begin{abstract}
Along with the change from elite-orientation to mass-orientation of higher education, the society asks different requirement on undergraduates and applied talent cultivation becomes the target of a glittering array of colleges. Laboratories are important channels to cultivate both the practice and innovation ability, which is of pivotal importance in the higher education transformation period. This paper analyzes the existing problems of laboratory construction in application-oriented colleges and come up with relevant measures as well as methods in terms of laboratory hardware construction and management, curriculum system setting, and faculty development for the laboratory construction innovation of application-oriented colleges.
\end{abstract}

\section{Introduction}

In recent years, the economy is rapidly developing, and the reform is getting deepened while the economy is approaching transformation, which asks different requirement on talents, especially asks higher requirement on the practical ability of science and engineering talents. Colleges, as the place to cultivate and output talents should pay attention to cultivate applied talents with innovative abilities. Concerning science and engineering colleges, we have to combine project practice and construct application-oriented laboratory to strengthen the ability of students, which is the key of cultivating applied talents. In order to cultivate applied talents, colleges should invest a lot to build laboratories, change the teaching mode of taking theoretical teaching as the core, add the percentage of practical teaching and improve its quality to enable students with the ability of mastering both the knowledge and theory and practice. Therefore, college laboratory is an important platform for practical teaching, which is also the basis to improve practice and innovation ability, and an important means to guarantee the quality of practical teaching.

\section{Transformation Condition of Undergraduate Colleges}

Stages of Undergraduate College Transformation. Since the reform and opening-up in China, the development of higher education is facing a new stage. What's more, with the deepening of structural reform of education, the higher education changes from elite-orientation to mass-orientation. During this period, the number of colleges is soaring, and new colleges occupy one-third of the total number, becoming new force of cultivating talents in the new era. However, many colleges are in the first development stage and they follow the old tradition of teaching-research type. However, with the deepening of reform and opening-up, the social economy should also change and the requirement on talents also changes. Especially for science and engineering talents, those with practical abilities are more favored, which encourages colleges to cultivate applied-orientation talents.

Concerning the undergraduate colleges transformation, there are two types: one is from junior college education to undergraduate; one is from teaching-research orientation to applied orientation. This paper mainly analyzes the second one, which is more complicated and difficult and should start from the perspective of teaching mode, and management. The target of applied colleges is to cultivate talents, who cans serve the local economy. After clearing this position, applied undergraduate colleges should pay more attention to the practical ability and the core of laboratory construction is to improve the practical and innovative ability of students. Therefore, in the process 
of transforming to applied undergraduate colleges, to study on laboratories and innovation constructions are very important sectors. Undergraduate colleges in the transformation period should clear their position, and try unremitting efforts to build laboratories with their own characteristics so as to create colleges with higher quality.

The Development Condition of Applied Undergraduate Colleges during Transformation Period. To begin with, most of the undergraduate colleges which need transformation are those improved from vocational high schools. In the beginning, they blindly expand, add schools etc, which blur the position of schools so that they are not competitive comparing to previous ones and they are inferior in terms of cultivating practical talents. As a result, many emerging undergraduate colleges do not have their own characteristics. Secondly, schools cannot combine the local economy features and self-development and they don't have special goals for students. Thirdly, the faculties in colleges during the transformation period are not powerful, and they lack experience in enterprises. Concerning applied colleges, we cannot only focus on their academic research ability but also highlight the importance of practical teachers, which can help students to find jobs in the society. Fourthly, comparing to previous colleges, the government does not give enough economic support for emerging ones. In addition, relevant enterprises should comply with the development of education development and change their mind to equally weigh teaching-research colleges and application-oriented colleges. The last but not the least, new colleges lack construction experience in terms of establishing practical ability training platform, so that students cannot have many opportunities to practice, which is very bad for cultivating students. Laboratories, as important bases for practical ability training, should be highlighted by colleges during the transformation period.

\section{The Current Condition of Laboratory Construction in Applied Undergraduate Colleges}

The Necessity to Construct Laboratories in Colleges. In short, applied talents cultivation is to train professionals who can combine theoretical knowledge as well as skills and can flexibly apply to social activities. Along with the development of social economy, there is an urgent need for talents in terms of science and engineering. Therefore, application-oriented colleges should pay more attention to cultivating the practical ability of these students and laboratories are the main channel to implement practical teaching. Undergraduate colleges should strengthen the construction of laboratories, improve the teaching ability, and fully play the function of laboratories. What's more, in terms of cultivating students, we should take advantage of solid theoretical knowledge to construct a professional structure along with laboratory practical training so as to help them apply theoretical knowledge into practical ability so that to make them more competitive. In addition, lab construction is also an important guarantee to help colleges change into application-oriented ones. Therefore, it is a necessary to cultivate applied talents in terms of science and engineering field.

Problems of Constructing Laboratories in Colleges. Firstly, the laboratory construction in applied colleges is not long and does not have a big scale while the management system is imperfect. When colleges start to carry out transformation, many colleges change their ideas and start to build laboratories. Even though the number is increasing, there are irregular because they don't have experience. What's more, the management system of lots of laboratories lags behind and the usage is improper and the teaching effect is not obvious.

Secondly, the equipment update speed of laboratory is not fast enough, which cannot meet the requirement of practical teaching. Due to the condition that government does not invest enough funds on colleges, the equipment in laboratories is old and some of them are abandoned ones, which will cause bad effect on the practical training effect and the result will be biased so the equipment cannot play its function. Besides, because of limited time, funds, place, equipment, students cannot carry out deep learning. What's more, the equipment software is not updated timely, which hinders the development of teaching contents and modes and it is difficult to carry out practical training and will weaken the ability of students' analyzing and discussing on experiment and is not beneficial to cultivate innovative thinking and independent thinking ability.

Thirdly, schools do not pay much attention to the laboratory teaching and the teaching mode is 
rigid. Even though the laboratories in undergraduate colleges develop a lot, the real effect is not obvious and traditional theoretical teaching mode is entrenched. Therefore, the idea of teachers and students cannot change in a short time. In terms of laboratory teaching, colleges do not pay much attention to it and the teaching mode teachers adopt is demonstration while students simulate. What's more, even though the number of big scale laboratories and students who can participate in laboratory learning is soaring, most of students can only watch and stimulate, they cannot really practice and cannot analyze the result. As a result, they have a random attitude toward experiment and only want to finish tasks; on the other hand, the overall quality of technical staffs in the laboratory is poor and teachers are dominant and students are passive; in addition, colleges do not train hard on technical staffs and their knowledge cannot keep pace with the time.

Finally, the current college laboratories lack comprehensive and design features and the importance of laboratories cannot be presented. Under the effect of traditional teaching mode for a long time, many colleges build laboratories for severing theoretical teaching, which can assist people and most of the experiments focus on confirmatory experiment. Students just stimulate what the teacher demonstrates without innovation. And students do not take the initiative to design, they just learn the theoretical knowledge to deal with examinations. Therefore, it is difficult to apply theoretical knowledge into practice.

\section{Measures for Laboratories Construction in Application-Oriented College}

Improve the Awareness of All People, Focus on Laboratory Practical Teaching. In China, colleges are in an important period of transformation and all colleges should clear their position to vigorously develop laboratories, focus on practical teaching and develop into application-orientation colleges. Under such circumstance, colleges should update their ideas, improve the recognition on practical teaching and put laboratory construction in a very important place so as to guide students to positively join in practical teaching and improve the teaching effect.

Perfect the Laboratory Management System; Improve the Utilization Rate Of Laboratories. A laboratory with scientific and regular management is the guarantee for high quality development of college laboratory. Management on the laboratory can help to improve the knowledge of management personnel. By adopting the scientific management means, we can control the utilization rate and scientifically maintain precision instrument, timely update equipment which are frequently used, record the equipment with low usage. Based on this, we can make the purchase plan next year to carry out optimal distribution and improve the usage rate. In addition, an overall plan on laboratories can help teachers to carry out practical projects and share the college laboratory recourses to a maximum extent and improve the teaching quality.

Increase Investment for Laboratory Construction, Timely Update Laboratory Equipment. Undergraduate colleges should try their best to win the economic support from government and enterprises. At the same time, they should pay more attention to laboratory construction and increase the investment on laboratory equipment, timely update hardware and software, regularly maintain precision equipment so as to increase the service life, which is positive for students to do experiment. Meanwhile, we can carry out a cooperation mode between schools and laboratories so as to effectively transfer the experiment teaching into industrial value to attract the investment of the society and enterprises. Based on this, we can encourage colleges to carry out practical teaching, which can also advocate the value and meaning of practical teaching.

Perfect Laboratory Teaching Mode, Focus on the Construction of a Comprehensive and Creative Laboratory. Affected by the traditional teaching mode with theoretical knowledge as the core, the laboratories can only assist and it's most function is to let students do confirmatory experiment, aiming to let students understand the theoretical knowledge via teachers' demonstration. It actually cannot help to play the function of laboratories. While transferring into application-oriented colleges, the nature of laboratory construction is to cultivate all-round talents with innovative abilities. Therefore, in laboratory teaching, we have to change the teaching mode which used to take teachers as the core and take students as the focus. In addition, while carrying out course design, teachers should add some experiment which can stimulate students' independent 
thinking ability and initiative so as to let them fully analyze and think to apply theoretical knowledge into practice. Therefore, in college laboratory construction, we should not only focus on the soaring number of laboratories but also pay attention to the focus of comprehensive and creative design so as to improve the practical teaching quality.

Strengthen the Team Construction of Laboratories, Improve the Laboratory Teaching Quality. The team construction of laboratory includes faculties and technical staff training. On the one hand, we have to encourage teachers to increase the percentage of practical teaching but also improve the teaching quality. What's more, while enrolling teachers, colleges have to pay attention to their practical experience; on the other hand, colleges should also take into account the quality of laboratory staffs, carry out regular training, improve the management and maintenance, save costs and improve the passion of students. Furthermore, colleges can also set some positions like laboratory assistants for students so as to encourage them to join the daily operation to strengthen their passion and experience on practical training.

\section{Conclusions}

Application-oriented colleges emerge with the development of social economy, which is also an inevitable outcome of higher education development as well as reform. In the critical period, undergraduate colleges should focus on the meaning and value of laboratory construction to successful transformation and they should positively construct laboratories so as to lay a solid foundation to cultivate all-round talents.

\section{Acknowledgements}

Teaching and Research Project: Liaoning Education Science 13th plan of five-year's Project Study on the Laboratory Construction Innovation of Application-oriented Colleges in Transformation Period (JG16EB037)

\section{References}

[1] Z.L. Lu: The Stages of Emerging College Transformation, Journal of Changshu Institute of Technology (Education Science), December 2012, Term 12

[2] S.L. Cheng: Challenges and Opportunities of Application-Oriented Colleges in Transformation Period, Wenhui Science, November 2014 (I), Term 295

[3] F.W. Peng, W.J. Wang, N. Li, X.J. Zhou and Z.H. Wang: Problems and Countermeasures for the Laboratory Construction of Local Economic and Management Schools-Take Hunan Institute of Humanities Science and Technology as an Example, Journal of Hunan Institute of Humanities Science and Technology, Term 6 December 2014

[4] C.L. Yan, X.R. Li, J.N. Zhang and C.M. Yang: Management and Construction of Local Application-Oriented Colleges, Laboratory and Trainning Base Construction, Term 221 July 2015

[5] Baiyu, Sang Nan. Exploration and Practice on the Laboratory Opening of Application-Oriented Colleges, China Modern Educational Equipment, Term 227 October 2015 